\title{
Mitologia do Caos no Romantismo e na Modernidade
}

\author{
WINFRIED MENNINGHAUS
}

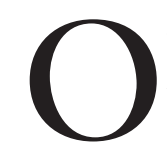

S CONCEITOS ANTIGOS de cosmologia, quando se diferenciam em disciplinas individuais, são geralmente fadados a sobreviver apenas como literatura e mitologia. O caos e os conceitos que se the opõem de ordem e di-

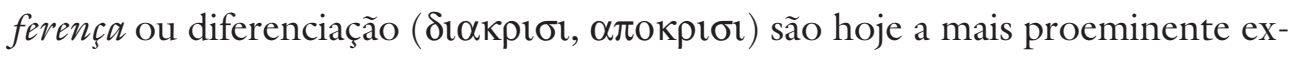
ceção à regra.

Nas duas últimas décadas, a filosofia, a literatura, as ciências naturais e a matemática voltam novamente a convergir no emprego desses conceitos como sistemas fundamentais de investigação para descrever o mundo. A noção de caos reconquistou tanta importância e está tão presente que voltou a ter um valor $\mathrm{e}$ uma função ideológica secundária e funciona como um enfoque da auto-reflexão do Zeitgeist da atualidade.

O impulso decisivo para a popularidade repentina do caos nos dias de hoje veio das teorias de sistemas não-lineares e dos processos biológicos de autoorganização. Descobriu-se, em muitas áreas, que até mesmo sistemas estritamente deterministas tomam um rumo imprevisível; que a ordem sempre se torna novamente caos ao mesmo tempo em que também sempre emerge autopoeticamente das estruturas caóticas. Em conseqüência, desenvolveu-se nova e estimulante ciência das bifurcações imprevisíveis, indeterminadas e inderiváveis. Hoje ela perpassa todos os campos científicos em tal grau que um Michel Foucault do final do século XXI talvez pudesse considerá-la o dispositif arqueológico epistêmico do final do século XX.

A pesquisa do caos na matemática e nas ciências naturais, todavia, não é o tema de minha palestra. Meu único intuito é analisar aquelas retomadas do caos que ocorreram mais ou menos simultaneamente nas ciências humanas: as concepções filosóficas, sociológicas e estéticas do caos. O material que utilizo deriva de três concretizações principais do caos: a cosmologia clássica de Hesíodo e Ovídio, a reinvenção programática do caos como um dos conceitos centrais da filosofia $\mathrm{e}$ poética dos primeiros românticos alemães, e a retomada mais recente do caos e da diferença na desconstrução de Jacques Derrida e na teoria dos sistemas de Niklas Luhmann. As observações voltam-se primeiro para a lógica fundamental, depois para a estética e finalmente para a ética ou ideologia do pensamento do caos. 


\section{Demarcações de fronteiras entre caos e ordem}

Os dois primeiros versos das Metamorfoses de Ovídio narram a origem do mundo criado a partir do caos: "Antes de existirem o oceano, a terra e os céus cobrindo tudo / a Natureza mostrava apenas uma única face no mundo inteiro. / Caos era seu nome: uma massa bruta, informe, / nada mais que um peso inerte e, nele acumuladas, / as sementes das coisas, num grande amontoado." (vv.5-9).

Esse grande amontoado (congeries) cheio de potencial e de semina rerum é "dividido e separado e depois ordenado em segmentos" por um deus: quisquis fuit ille deorum (vv. 32-33). Fica assim evidente a direção temporal: primeiro o caos; em seguida, depois que ele foi separado e superado: o cosmos. Os dois definem diferentes eras do mundo e, embora procedam um do outro, cada qual em sua estrutura é precisamente o oposto do outro: no caos há potencialidade na forma de indiferença; no cosmos há realidade na forma de diferença. A concepção moderna de caos afasta-se dessas duas determinações básicas do modelo mitológico. Já não obedece ao movimento temporal de mão única do caos para o cosmos, mas assume a direção contrária além de aceitar uma oscilação permanente entre os dois pólos. Assim, o próprio caos, pela primeira vez, recebe uma bistória. Em Hesíodo e Ovídio ele é de fato parte de uma narrativa mitológica, mas ali o caos não tem gênese alguma. Muito pelo contrário, é a base opaca e primária, o pressuposto pré-histórico de toda gênese e apenas o seu desaparecimento, que constitui a origem do mundo, entra na narrativa cosmológica. As teorias do caos de hoje, no entanto, narram a gênese sempre nova do próprio caos, e, dessa forma, pela primeira vez nos fornecem a sua genealogia. Além disso, atualmente, a diferença entre caos e cosmos recorre dentro das próprias definições de caos e ordem: já não existe nenhum caos puro e nenhuma ordem pura. Finalmente, as novas formas de caos associam as características de fertilidade e vida, ao passo que a fertilidade do caos ovidiano era em si mesma contrária à vida; o mundo só poderia tornar-se habitável para os deuses do Olimpo e para os seres humanos mediante a negação do caos. Gostaria agora de sugerir como a cosmologia antiga já antecipa essas complexas demarcações de fronteiras entre o caos e a ordem.

Na Teogonia de Hesíodo, já desde o princípio o caos não é absorvido pela diferenciação do mundo. Ao contrário, o caos primogênito e seus sucessores, a negra Noite, o Érebo e várias outras monstruosidades nefandas constituem uma sinistra contrapartida do mundo diferenciado. O mundo positivo, isto é, o oceano, os céus, as montanhas, Urano, Cronos e os deuses do Olimpo não emergem do caos, mas de Gaia, que foi a segunda a nascer de forma autóctone. Mas é interessante ver como os descendentes do Caos e de Gaia não se isolam simplesmente em duas séries opostas, mas se entrelaçam em vários momentos. Assim os 
netos do Caos, isto é, os descendentes dos filhos do Caos, Érebo e a negra Noite $(\mathrm{N} v \xi)$ incluem o azul celeste $(\mathrm{A} \imath \eta \eta \rho)$ e o dia claro $(\mathrm{H} \mu \varepsilon \rho \alpha)($ vv. 123-125) fenômenos, portanto, que não perpetuam a série negra, mas, pelo contrário, a transformam invertendo-a em seu Outro. Tudo o que a luz do dia nos permite ver permanece como tal iluminado por sua descendência do caos. Por outro lado, Gaia gera também a tribo sinistra de Erínias (v. 185) e seus netos incluem todos os tipos de criaturas monstruosas tais como o Cérbero de cinqüenta cabeças e a Hidra, cuja própria ausência de molde se torna molde, cuja caótica amorfia se torna forma (vv. 295-315). Embora não haja qualquer cruzamento direto dos descendentes do Caos e de Gaia, tanto suas características como seus domínios se entrecortam; ao invés de saírem um do outro para depois se separarem, ambos continuam em permanente interação. Ovídio também nos permite reconhecer em seu quadro do Dilúvio uma espécie de retorno do Caos, e nas ocasionalmente bizarras metamorfoses de personagens mostra uma espécie de presença contínua do Caos (1).

No pensamento romântico inicial a intervenção do caos no sistema conhece uma legitimação multíplice. Para os primeiros românticos, sistemas cuja autoreferência não sofra constantemente uma interrupção caótica não permitem quaisquer vida, variedade e abundância de fenômenos. Em oposição à ordem rígida na política, na filosofia e na literatura, Friedrich Schlegel e Novalis exigem nova mistura de caos e ordem. Ordem e sistema já não significam a diferenciação do caos mas, ao contrário, tornam-se por sua vez - e aqui há plena consciência do conceito de mistura da química contemporânea - misturas de caos e ordem. $\mathrm{O}$ insistente pedido romântico de novas e mais complexas demarcações de fronteiras entre a ordem e o caos tem dimensões filosófico-transcendentais, estéticas e histórico-filosóficas; aqui considerarei antes a primeira e a terceira dimensão.

O ponto filosófico-transcendental de um "sistema de filosofia caótica" (2) baseia-se no discernimento crítico de que os sistemas filosóficos não podem explicar a "realidade", a "totalidade" e o "Absoluto" precisamente na medida que suas construções conceptuais estão cegas para as suas próprias idealizações - e isso se assemelha à maneira em que a atual teoria do caos critica as idealizações e, conseqüentemente, a irrealidade normativa da física clássica. "Se algo é um sistema," infere Schlegel impiedosamente, "não é absoluto. A unidade absoluta seria algo como um caos de sistemas" (3). Não é, portanto, um capricho romântico, mas, precisamente, um interesse epistemológico que leva os românticos a romperem muitas e muitas vezes formas fechadas e unificadas. Parábase e ironia são nomes que se dão a essa interrupção e destruição positivas. No contexto da comédia de Aristófanes a parábase era uma interrupção da ação quando o coro se dirigia ao público (4); a parábase produz desse modo interrupções na seqüência da ilusão dramática. Além disso, a ironia confunde todas as diferenciações fixas de $=\mathrm{e}-(5)$ e produz aquela codificação dupla que levou Schelling a identificar o 
caos com a face de Janus (6). Exatamente como a promessa ontológicoepistemológica, assim também a promessa filosófico-histórica na produção do caos não hesita em transformar as outrora negativas associações de anarquia e revolução (7) em valores positivos. As formas de abstração que eram sentidas como inumanas, feias e desprovidas de sentido, e cujo contexto histórico se descreve como um caos negativo (8) passam a ter novo apelo e nova vida mediante uma caotização repetida. Esse relançamento reflexivo do caos, confiavam os românticos, abre a possibilidade de uma mistura bonita de caos e ordem, permitindo que a arte e a vida se beneficiem com um horizonte indeterminado, com um posicionamento incerto entre extremos e transições sempre novas. Nessa mistura não é apenas a ordem que está permeada de caos: o caos também sempre traz consigo uma ordem. É, como Schlegel disse uma vez, "simetricamente caótico" (9).

Para o projeto romântico de criar nova mitologia que proporcionasse "um novo leito e um novo recipiente para a antiga eterna fonte da poesia (10)", a liberação do caos tem conseqüências interessantes. Por um lado, a nova mitologia deveria compensar a desorientação do caos da época e fornecer um fundamento que fosse nova base comum e fator de unidade. Por outro lado, o retorno de uma idéia recuperada do caos no âmbito do remédio contra o caos impede qualquer estabilização restauradora da mitologia positiva do início do romantismo. A mitologia do caos é até esse ponto uma espécie de mitologia que não libera nenhuma entidade mitológica estável, mas, pelo contrário, substitui o fundamento perdido da modernidade apenas na forma de uma permanente autodesestabilização dos fundamentos.

A desconstrução, segundo o pensamento de Derrida, descobre em todas as ordens aparentemente fechadas e oposições estáveis aspectos que lhes minam e finalmente apagam o controle. Nesse sentido a desconstrução continua o projeto romântico de entremesclar toda identidade e todo sistema com tendências caótico-centrífugas. Essa entremesclagem, porém, já não está ligada a qualquer espécie de intencionalidade ou a qualquer tema romântico que seja, mas tende pelo contrário a ser concebida como um acontecimento inevitável, atemático, de toda textualidade, sobre o qual podemos no máximo nos iludir a nós mesmos, mas cuja produção não depende de nós. Porque o ato de articulação que, na famosa imagem de Saussure, extrai unidades distintas de uma nuvem disforme de idéias, ao estabelecer forma distinta imediatamente produz outra vez efeitos de caos. Prendendo irremediavelmente todo significante a marcas de significação que, por sua vez, estão presas a todas as outras marcas arbitrárias da linguagem e disponíveis para repetição em outros contextos, noutras ocasiões, a articulação impede a unidade de um pensamento ou de uma idéia consigo mesma e a consigna à trajetória de contingência e hetoronomia insuperáveis. Efeitos análogos ao caos - que, obviamente, em geral não circulam sob esse nome - são assim tematizados pela desconstrução não como o Outro e mero substrato da ordem 
ou como sua delimitação externa, mas, antes, como algo que sempre já habita a própria ordem em si. A fusão de oposições estáveis e a indeterminação são efeitos da própria diferença ativa e não da ausência transcendental de diferenciação no sentido das antigas cosmologias. Essa variação do conceito de caos orientada para a linguagem foi antecipada por Schlegel quando estabeleceu um paralelo entre a oposição de caos e sistema e a oposição de letra e espírito [Geist] (11). A letra, sem a qual não há espírito algum para os românticos, é ao mesmo tempo aquilo que caotiza a ordem do espírito, sua auto-identidade.

$\mathrm{Na}$ desconstrução o caos torna-se, conseqüentemente, um efeito da diferença e, portanto, um acontecimento no âmbito da própria ordem. A teoria avançada de sistemas (Maturana, v. Foerster, Luhmann) partilha com a desconstrução da percepção da instabilidade básica de sistemas altamente complexos e da inderivabilidade de acontecimentos sistemáticos. Como a desconstrução, a teoria de sistemas concebe o funcionamento de sistemas não a partir da perspectiva de um sujeito, mas, antes, a partir de uma diferença operativa (embora com certeza essa operação seja concebida funcionalmente). A teoria sociológica de sistemas tomou emprestada a teoria da auto-organização bem como a concepção de um caos determinista sobretudo da biologia, ao passo que a desconstrução os desenvolveu sem contato algum com as ciências naturais. A teoria de sistemas integra precisamente a imprevisibilidade dos acontecimentos ao funcionamento de um sistema e, com isso, demonstra sua flexibilidade e capacidade de processar informação e evoluir; os efeitos do caos no sentido da desconstrução, todavia, são concebidos mais em termos de ruptura e subversão do que de possibilitação do funcionamento e da evolução de uma ordem complexa. Portanto, a teoria dos sistemas não está absolutamente preocupada em enfeitar a presença do caos no sistema como alguma forma de resistência filosófica ou política, como fazem os românticos e alguns desconstrutivistas.

A teoria dos sistemas sociológicos mostra que uma ordem pura não existe, nem pode ou precisa existir - pelo menos como uma ordem impermeável à desordem e ao caos. Além disso, a ordem que simplesmente exclui o caos funciona pior do que a ordem que a ele permanece aberta e para ele está sempre orientada, cuja auto-referência assim permite uma referência flexível ao outro. No contexto da teoria dos sistemas dinâmicos o caos é de fato celebrado no sentido de uma "estética de risco (...) como o próprio modelo do que estimula a vida (...) Perigos de incertezas transformam-se em possibilidades de surpresa" (12). Nessa perspectiva de uma afirmação de abertura, imprevisibilidade e risco, podemos hoje detectar a instigante perplexidade do caos romântico (13) sem termos de abraçar seu projeto desesperadamente utópico. As faces escancaradas de Hesíodo e o grande amontoado de Ovídio tornam-se o elixir não do demônio ou da arte, mas de uma ação que exitosamente se conforma com a realidade. Enquanto a desconstrução interpreta a desfiguração e a indeterminação textual - fenômenos 
análogos ao caos - como inextricável areia na caixa de câmbio de oposições metafísicas, na teoria dos sistemas o caos torna-se insumo indispensável e horizonte evolucionário da própria ordem.

\section{Caos e beleza}

Desde a antigüidade clássica a distinção de caos e cosmos tem extremo

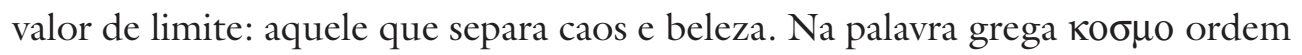
e beleza se interpenetram. A ordem harmoniosa dos sons na música e a harmonia das esferas do cosmo são, desde Pitágoras, paradigmas centrais de um conceito de ordem, que está aliado à beleza. A beleza realizada em sons e formas é aquele predicado da ordem em que a origem da ordem a partir do caos aparece mais significativamente superada, até mesmo apagada. O fato de que Afrodite deve seu nascimento à castração de um pai divino por seu filho, de que a espuma da qual ela emerge venha da semente de órgãos sexuais desmembrados em vez de simplesmente do suave ondulado Ägäis, fica absolutamente negado e ofuscado na beleza de sua forma. Contudo, a deusa da beleza atesta sua afinidade com o caos não apenas em virtude de sua origem, mas também em seus efeitos. Ela é o mais forte estímulo de Eros e, portanto, um poder que muitas e muitas vezes supera o impulso da autopreservação e traz morte às suas vítimas. A beleza de Helena lança todo um mundo na morte e no caos; a Atalanta de Ovídio faz com que uma série de seus pretendentes aceitem a sorte mortal que ela oferece. De maneira realmente paradigmática as sereias combinam a beleza, a promessa de conhecimento e a ameaça de morte. A beleza aparece em todos esses exemplos como parte de uma economia dinâmica, na qual a maior distância do caos funciona simultaneamente como agente de destruição de ordens estáveis e de sua nova precipitação no caos. (Simultaneamente, os exemplos aqui apresentados indicam a íntima conexão entre o caos e o feminino.)

Nietzsche, por esse motivo, pôde entender a beleza da arte grega como aparência apolínea, como contrapartida e véu de uma violência dionisíaca (14). O princípio anticaótico de distinção e individuação e o caos dançante sem limites e sem contornos são, nessa visão, correlatos diretos ao invés de oposições estáticas. De fato, de acordo com Nietzsche eles não têm existência independente sem seu respectivo Outro, e a arte muitas e muitas vezes produz as transformações e transições entre eles (15). A poderosa dinâmica e transitoriedade da beleza, o lado reverso de toda a aparente estabilidade da figura belamente proporcional, tem sido repetidamente objeto de reflexão na história da estética. Edmund Burke enfatiza isso quando observa que "a brevidade da vida" é uma característica integral dos objetos que nós sentimos mais intensamente como belos (16).

Na poética do século XVIII a beleza é, desde o início, concebida como uma tensão entre ordem e desordem. Na estética francesa e na do classicismo alemão, a ordem domina sem ambigüidade, mas nunca extirpa completamente 
os aspectos de desvio e desordem, a linha imprevisivelmente torta. Essa importância de un beau dèsordre cresce cada vez mais à medida que o século XVIII se aproxima do fim; no romantismo inicial ela obtém a igualdade com sua contrapartida, a ordem, e além disso até predomina sobre esta na polêmica fórmula "Poesia $=$ Caos" (17). Antes de os primeiros românticos oferecerem a surpreendente senha de "caos e sistema" para a bela interação de ordem e desordem, essa interação era negociada sob outros numerosos rótulos. Um dos conceitos centrais, entre os quais o je ne sais quoi da beleza manteve uma conexão subterrânea com o caos, é o despretensioso conceito de multiplicidade [Mannigfaltigkeit]. Simplificando, pode-se dizer que o sobrecarregado par conceitual de unidade e multiplicidade articula a variação do par contrastante de ordem e caos. Pelo menos assim era para Novalis e Ludwig Tieck, os quais apertaram tanto o parafuso da multiplicidade que, no fim, ele já não podia mais ser integrado na unidade de uma ordem.

Nessa hiperbolização anticlássica que atinge o ponto da assim chamada multiplicidade "infinita" facilmente emergiu uma elaborada retórica do caos e a idéia de obras que, nas palavras de Novalis, não deveriam apresentar "nenhuma coerência" e, portanto, nenhum "significado" (18). Ludwig Tieck interpretou esse estilhaçamento de unidade e coerência de duas maneiras: como um ajuste realista à vida que segue seu curso de modo exatamente caótico e sem sentido, e como uma emancipação positiva da literalidade, livrando-se das limitações do significado, como a apercepção de uma dimensão de absurdo que se prova poética precisamente em sua anarquia (19). Tal carta branca para o caos ao mesmo tempo leva o mito hermenêutico de uma compreensibilidade infinita ao seu ponto extremo. "A compreensão do caos," F. Schlegel laconicamente informa ao nosso desejo de compreender, "consiste no reconhecimento," e constitui "um estágio elevado, talvez o estágio final, na formação do espírito que por si mesmo postula a esfera da incompreensibilidade e confusão" (20).

Uma das apercepções paradoxais com efeitos duradouros da poética romântica é que o aumento do caos caminha junto com o aumento de um princípio de ordenação da arte, tão antigo quanto a própria arte: isto é, o princípio do paralelismo, da duplicação, da repetição. Os românticos já não precisam de estratagemas de irregularidade para conceber os efeitos imprevisíveis do caos: antes os descobriram na duplicação infinita, na serialidade de repetições. A duplicação auto-reflexiva foi, para eles, a lei fundamental da auto-referência artística, e precisamente essa lei lhes garantiu não uma ordem fechada, mas a abertura caótica de obras na direção de um jogo sem limites. Pois cada repetição significa também interrupção, ruptura de um movimento e novo começo em lugar diferente, em tempo diferente, e com suposição de um antecedente diferente. Uma vez que a repetição acarreta desvio e diferença, para os românticos a duplicação progressiva implica um fator de caos - exatamente como hoje nas equações 
iterativas da matemática do caos, na similaridade auto-reflexiva das fractais ou na descrição biológica de um fenômeno de cópia nunca absolutamente exata na auto-reprodução de organismos vivos (21). Particularmente, a lei da duplicação reflexiva abre um espaço genuinamente romântico para a anarquia poética e libera frêmitos de perplexidade.

\section{Teorias modernas do caos}

\section{e o campo das ideologias político-sociais}

Os atuais pesquisadores do caos geralmente não sabem o quanto seus modelos básicos repetem a filosofia e a estética do romantismo inicial que, por sua vez, se caracteriza pela adaptação de um legado místico. As conexões variadas e óbvias entre a teoria do caos e a doutrina dos Novos Tempos eclipsaram e ofuscaram a afinidade subterrânea entre os novos paradigmas científicos e o projeto romântico inicial. O triunfo do discurso sempre novo e velho do caosé, todavia, por demais extenso para ser adequadamente explicado como uma mera retomada histórico-intelectual do romantismo ou do misticismo. É exatamente tão impossível explicá-lo somente com base na lógica autônoma das ciências, particularmente porque a superestrutura especulativa da mais recente teoria do caos desenvolveu-se em razão inversamente proporcional ao ainda minguado estoque de seus resultados rigorosamente científicos. Assim, deve-se fazer a pergunta: que experiência histórica, que necessidade coletiva e que discurso técnico-social correspondem à súbita explosão de popularidade do caos? (22) Essa mudança de enfoque do nível teórico para o sintomático status cultural da teoria do caos não pretende absolutamente negar ou diminuir seu abrangente valor científico, que até agora não pode ser calculado com exatidão. Pois todas as revoluções científicas são afetadas por códigos culturais secundários; de fato, muitas dessas revoluções só se tornam possíveis por mudanças prévias no horizonte cultural. Exatamente como, por um lado, a teoria do caos seria impossível sem as possiblidades técnicas mais recentes no processamento e simulação gráfica de enormes quantidades de dados, assim também, por outro lado, seu sucesso na mídia, sua proliferação que beira a histeria pressupõe um dispositif no âmbito da consciência social.

Em termos de Lebenswelt a elevada consciência do caos é primeiramente um correlato direto da globalização de ordens que, nas últimas décadas, cresceu enormente. As redes financeiras, informático-tecnológicas e econômicas criam enormes possibilidades de ação, mas também enormes suscetibilidades de ruptura. Um erro nos computadores militares e a confusão será abruptamente total. Xeques árabes fecham a torneira do petróleo e indústrias essenciais do Ocidente entram em parafuso. A consciência ecológica está particularmente familiarizada com o efeito borboleta: cadeias alimentares inteiras podem ser destruídas pela remoção ou pelo acréscimo artificial de um elo; já não podemos usar um recipiente de aerosol sem pensar no buraco na camada de ozônio sobre a Antártica. 
Por isso é ainda mais assustador que essa afinidade entre caos e catástrofe não desempenhe papel algum nas teorias do caos da atualidade. Mais ainda: é precisamente do fardo de tal afinidade que essas teorias nos libertam. As teorias do caos exibem elegante função compensatória do caos, o que simplesmente parece paradoxal. Suas variantes tecnológicas reforçam nosso otimismo de que até nos fenômenos universais mais irregulares pode-se descobrir ordem ou, pelo menos, as forças de auto-organização no âmbito do próprio caos merecem confiança. E suas variantes intelectuais e ideológicas tendem a celebrar precisamente o fim de ordens fechadas como uma emancipação positiva. Ambas acreditam que o caos vivo, em sua incontrolável abundância, possui todas as forças benéficas que outrora pertenceram à garantia de ordem. Elas são marcadas por um ethos nietzscheano de uma afirmação anti-idealista do mundo em sua existência, que jamais é completamente controlável e está cheio de estranhos atrativos. E exatamente quando nos inclinávamos para a resignação ante à rápida uniformização do mundo das aparências, que a teoria do caos nos ensina a ver em toda parte, mesmo em fenômeno aparentemente simples e mais homogêneo, diversidade, diferença, e até turbulência. Estranhos padrões em líquidos turbulentos tornaram-se um emblema do mundo. O mundo é infinitamente variado, instigante e imprevisível: com essa visão das coisas a teoria do caos nos liberta até de opressiva suspeita de monotonia; liberta-nos daquilo que Adorno denominou o poder do princípio moderno de identidade. Mais ainda, a teoria do caos salva a singularidade e a irredutibilidade das aparências e, ao mesmo tempo, satisfaz nossa necessidade de uma teoria universal. Propõe padrões universalmente válidos, mas liberta todos os fenômenos da obrigação de tomarem posição determinada e previsível dentro de um padrão. Isso permite que a teoria do caos, de modo extremamente elegante, mantenha respeito pela singularidade do real e simultaneamente proporcione padrões ahistóricos de estrutura.

Desde que as ciências naturais e a matemática passaram a definir o paradigma do conhecimento e também, cada vez mais, o Lebenswelt, elas moldam nossa visão de mundo e nosso princípio de realidade tout court. Tornaram-se provedoras dos mitos básicos da civilização moderna. Como uma conseqüência de Newton, estes foram os mitos do determinismo: previsibilidade, planejabilidade, exeqüibilidade controlada. Sem o conceito de tempo e sem a capacidade de planejar o futuro nele implícito, até mesmo as amplas teleologias políticas e sociais teriam sido inconcebíveis. Com a teoria do caos, portanto, não apenas o paradigma do conhecimento científico-natural, mas também os mitos básicos da sociedade que o acompanham, sofrem mudança fundamental. Cada vez mais essas codificações secundárias da concepção do caos perdem sua ambivalência inicial e se cristalizam numa nova ideologia básica de vida, de ação social e de seu significado.

O caos do trânsito urbano e a confusão do mercado, o caos político e econômico em muitas partes do mundo e as possibilidades de colapsos ecológicos 
são qualquer coisa exceto fenômenos confortantes. Apesar disso, a popularidade repentina do caos provoca cada vez menos efeitos de ansiedade e incerteza. Mais do que tudo, alivia e suaviza a disposição das sociedades capitalistas dos últimos tempos e lhes dá, simultanemente, a expectativa tensa e relaxada de viver uma ética e uma estética de riscos sempre novos: assim, ainda existe um futuro imprevisível, ainda há horizontes abertos, o drama do mundo ainda não chegou à cena final. Um dos mais surpreendentes e ideologicamente mais densos desdobramentos de uma teoria de sistemas é o fato de que seu modelo de auto-organização, precisamente na medida que admite indeterminação e imprevisibilidade, também descreve as leis naturais da matéria viva, a natureza da beleza e o modo funcional das sociedades modernas. Esse tipo de mitologia moderna do caos é o complemento do atual retorno de mitologias de povos, nações e raças. As duas coisas reagem de formas diametralmente opostas a uma experiência semelhante de desorientação e deslegitimação. Mitologias restauradoras constróem estruturas ideológicas de orientação; de maneira inversa, a teoria do caos redefine, se assim quisermos, o próprio mal como valor positivo. Convida-nos a aceitar a inderivabilidade, a imprevisibilidade, a incerteza e as trajetórias caóticas como as próprias características da vida e como a oportunidade de liberdade, em vez de depender de origens estáveis e teleologias. Sem dúvida, essa é a opção mais filosófica e também, certamente, mais moderna do que as sempre velhas e novas mitologias de nação, povo e raça. Mas, contudo, também isso é uma mitologia: pois a imprevisibilidade, a turbulência e as próprias trajetórias aberrantes estão se tornando padrões estáveis de realidade e de expectativa. Ou, por outras palavras: a própria abertura simplesmente deixa de ser abertura e torna-se, em vez disso, ideologicizada como tal e conseqüentemente também substancializada.

Se por um lado o progresso na análise de processos vivos é indiscutível, e sua transferência para a teoria de sistemas sociais funcionais muito plausível, por outro lado a linguagem de sua descrição em muitos textos de teoria do caos escorrega diretamente para a ideologia. Autodeterminação, auto-renovação, oportunidade da inspiração individual e criativa contra a lei das massas: o aspecto de caos em toda auto-organização, nesses conceitos, recebe a outorga de dignidade de um modelo iluminado, neoliberal; isso, depois que a história finalmente nos emancipou de todas as utopias de eudaimonias planejadas e de todas as exigências do pensamento teleológico, é autocomplacência. Como o Doppelgänger da teoria da auto-organização não-mecânica, a teoria do caos está se tornando tácita e abertamente o provedor de uma ideologia depois do fim de todas as ideologias. Para infortúnio de todas as teorias do caos das ciências naturais, elas penetram a consciência geral apenas na forma dessa exploração ideológica, e para isso contribuem pesadamente. Suas parentes nas humanidades correm o risco ainda muito maior de bancarem o bobo do zeitgeist, apesar de seus respectivos avanços no conhecimento. Seja como for, elas não estão prestes a dar à luz "uma 
estrela dançante", como Nietzsche exigia daqueles que "ainda trazem o caos dentro de si” (23).

\section{Notas}

1 Não posso considerar aqui a importante teoria do caos de Anaxágoras. Cf. Otto E. Rössler. Endophysik. Die Welt des inneren Beobachters. Berlim, Merve, 1992.

2 Kritische Friedrich-Schlegel-Ausgabe. Von Ernst Behler unter Mitwirkung von JeanJacques Anstett und Hans Eichner (orgs.). Munique/Paderborn/Viena/Zurique, Schöningh, 1958 e v. 18, p. 111.

3 Ibid., v. 12, p. 5.

4 Ibid., v. 11, p. 88.

5 Ibid., v. 18, p. 77.

6 Cf. F.W.J. Schelling. Philosophie der mythologie, von Schelling, K.F.A. (org.), Sttutgart, 1856. Reimpressão: Darmstadt, Wissenschaftliche Buchgesellschaft, 1973, v. 2, p. 600-614.

7 Kritische Friedrich-Schlegel-Ausgabe, v. 2, p. 312.

8 Cf. ibid., v. 1, p. 221-224.

9 Friedrich Schlegel, Literarische Notizen 1797-1801. Von Hans Eichner (org.). Frankfurt a. M./Berlim/Viena, Ullstein, 1980, n.1881.

10 Kritische Friedrich-Schlegel-Ausgabe, v. 2, p. 312.

11 Idem, v. 18, p. 277.

12 Norbert Bolz. Die Welt als Chaos und Simulation. Munique, Fink, p. 18-20.

13 Kritische Friedrich-Schlegel-Ausgabe, v. 2, p. 318.

14 Cf. Friedrich Nietzsche. Die Geburt der Tragödie, em: F.N. Sämtliche Werke. Kritische Studienausgabe in 15 Bänden, von Georgio Colli un Massimo Montinari (org.). Munique, dtv, 1980, p. 9-156.

15 Friedrich Cramer também mostrou que a descrição formal da beleza como uma proporção da forma na versão matemática da "média de ouro" tende a ser equivalente a "o mais irracional de todos os números irracionais possíveis" (Chaos und Ordnung. Die komplexe Struktur des Lebendigen. Frankfurt a. M., Insel, p. 201). Depois disso ele chegou às mesmas conclusões para seres objetivos de beleza que são produzidos a 
partir de uma observação da violência de seus efeitos: a beleza é uma negociação de fronteira entre ordem e caos; a beleza surge não como o maior afastamento possível do caos, mas sim como um desvio mínimo dele (p. 202-205); a obra Fractal Geometry de Mandelbrot oferece exemplos fascinantes desses fenômenos.

16 Edmund Burke. A philosophical inquiry into the origin of our ideas of the sublime and the beautiful. James T. Boulton (org.). Londres, Routledge and Kegan, 1958, p. 116.

17 Kritiche Friedrich-Schlegel-Ausgabe, v. 18, p. 71

18 Novalis. Schriften. Die Werke Friedrich Hardenbergs, von Paul Kluckholn und Richard Samuel (org.), 2a. ed. Stuttgart, Kohlhammer, 1960 e ss., v. 3, p. 454 e 572.

19 Cf. Ludwig Tieck. Sümtliche Werke em 9 v. Berlim, Georg Reimer, 1828, v. 9, p. 193, $219,220$.

20 Kritische Friedrich-Schlegel-Ausgabe, v. 18, p. 227.

21 Cf. Cramer, Chaos und Ordnung, p. 46.

22 Cf. N. Kathrin Hayles. Chaos bound. Orderly disorder in contemporary literature and science. Ithaca/Londres, Cornell University Press, 1990. Minhas observações em vários pontos devem crédito a este estudo.

23 Nietzsche. Also sprach Sarathustra. Ein Buch für alle und keinen, em: F.N. Gesammelte Werke (Musarion-Ausgabe), v. 13, não consta editor, 1925, p. 13.

Winfried Menninghaus é professor da Universidade Livre de Berlim, Alemanha.

Palestra feita pelo autor no Instituto de Estudos Avançados da USP em 8 de junho de 1994.

Tradução do alemão para o inglês de Henry Pickford. Tradução do inglês para o português de Almiro Pisetta. O original em inglês - Chaos mythology in romanticism and modernity - encontra-se à disposição do leitor no IEA-USP para eventual consulta. 